\title{
A "classicidade" de Gramsci e o tema dos intelectuais ${ }^{1}$
}

Alberto Aggio*

Resumo. Discute-se neste artigo a condição de clássico da política do século XX atribuída a Antonio Gramsci por boa parte de seus interpretes. Realça-se a temática dos intelectuais formulada por Gramsci nos seus Cadernos do Cárcere procurando alocar a própria trajetória de Gramsci no interior dessa reflexão. Com isso se sugerem alguns elementos novos para uma discussão em torno do seu pensamento político bem como a respeito da sua incidência na reflexão crítica a respeito da relação dos intelectuais com a política na cena contemporânea, enfatizando a analise a respeito dos marcos específicos daquilo que Gramsci caracterizou como revolução passiva.

Palavras-chave: Antonio Gramsci. Classicidade. Intelectuais. Revolução passiva.

Aparentemente, estamos todos de acordo ao afirmar que toda uma época terminou. Mas, quando uma época termina, se não conseguirmos pensá-la com conceitos novos, diferentes daqueles que capturaram a mente de quem a viveu, das duas uma: ou não é verdade que ela terminou, ou quem continua a representá-la com os conceitos do passado talvez não saiba, mas na realidade morreu intelectualmente com ela (VACCA, 2009, p. 160).

\footnotetext{
* Departamento de História da Faculdade de Ciências Humanas e Sociais (FCHS) da UNESP, campus de Franca-SP, Professor Titular, albertoaggio@uol.com.br, Rua das Virtudes, 709, Franca, São Paulo, Cep. 14403-078.
}

Anos 90, Porto Alegre, v. 17, n. 32, p. 75-91, dez. 2010 
Antonio Gramsci é comumente considerado um clássico da política! Aparentemente consensual, a frase é, entretanto, agudamente polêmica, exigindo a advertência de que tal reconhecimento não é desprovido de dúvidas e de vigorosos debates entre visões distintas e até mesmo contrapostas. O primeiro e mais visível território para essas contraposições - sem que aqui tenhamos quaisquer intenções de esgotar tal abordagem - é aquele que se reporta propriamente ao texto gramsciano. Para Giacomo Marramao, Gramsci não possui uma concepção de totalidade, típica dos "clássicos" do século XIX. Para ele, o texto de Gramsci apresenta todas as indicações de que dificilmente poderia ser equiparado a um "clássico" no sentido oitocentista do termo uma vez que a sua obra explicita, de maneira flagrante, a "impossibilidade do sistema". Gramsci seria assim um clássico "no sentido estritamente novecentista do termo" (MARRAMAO, 1988, p. 151). Para outros interpretes, esse caráter fragmentário do texto gramsciano é apenas "aparente" e não impossibilitaria a percepção de uma formulação novíssima e bastante articulada que seu autor projetava para um século que recém se inaugurava com toda sua força e dramaticidade (LIGUORI, 2007).

Mas há outros campos nos quais a polêmica é muito mais áspera. Carlos Nelson Coutinho, por exemplo, desconfia da apresentação de Gramsci como um clássico, sem as devidas advertências e qualificações. Ainda que "aparentemente elogioso", o movimento de apresentação de Gramsci como um clássico no sentido de que ele se configura como um "interprete de seupróprio tempo que permanece atual em qualquer tempo" é, para Coutinho, uma "dissimulação" que tem como objetivo "desqualificá-lo como interlocutor privilegiado do debate político de nossos dias". Conforme o mesmo autor, Gramsci deveria ser pensado como clássico porque continua a ser um "interprete do nosso tempo", um pensador que refletiu sobre "um mundo que, em sua essência, continua a ser o nosso mundo de hoje" (COUTINHO, 1999, p. 256-257; grifos do original). Nessa leitura, Gramsci é um clássico porque fazemos parte do mesmo mundo em que ele viveu. Seu pensamento expressa a essência do seu mundo, que é enfim o nosso mundo, e por essa razão ele não se esgota e muito menos morre. Nessa leitura, não há como não se deixar dominar pela imagem de um Gramsci eterno. 
Todavia, Gramsci é morto! Entretanto, imersos nos labirintos de um paradoxo de natureza apenas formal, se entendermos que Gramsci efetivamente não está morto seria preciso então definir o que lhe dá vitalidade, considerando inevitavelmente que sua historicidade é determinada assim como seu mundo também o foi. Se por meio dele nos sentimos estimulados a pensar sobre o nosso tempo e sobre o novo mundo que se descortina a cada segundo diante de nós é porque seria um equívoco esquecê-lo, como já se tentou fazer algumas vezes (VACCA, 1991). Mas não seria sem propósito desconfiar de que tudo o que escreveu Gramsci no início do século XX tenha a mesma validade nos dias que correm.

Num texto recente, Giuseppe Vacca relembra a forma pela qual Valentino Guerratana, em 1991, se referiu à "classicidade" de Gramsci. Para o organizador da edição crítica dos Cadernos do Cárcere, Gramsci poderia ser considerado um clássico na medida em que "é um autor que vale a pena reler e reinterpretar a luz de novas exigências e de novos problemas". Esta seria, de acordo com Vacca, uma definição inteiramente válida para um "filósofo individual", mas questionável para um autor como Gramsci. Ainda que sem negá-la, seu argumento avança na seguinte direção:

Gramsci é um autor póstumo que não deixou "obras", mas uma imensa quantidade de escritos jornalísticos, de intervenções políticas, de cartas e apontamentos inéditos que constituem o calhamaço de manuscritos do cárcere. É, pois, um "clássico" inteiramente particular, cujos escritos tornam-se "obras" através do atento trabalho dos editores e cujo pensamento vive e muda segundo os progressos e as diferenças das suas edições (não há edição de um "clássico" na qual não se proponha também uma ou mais interpretações, e isso é verdade sobretudo para um autor como o nosso) (VACCA, 2010, p. 28).

Um clássico sujeito a um exercício reflexivo permanente e contínuo, Gramsci poderia, de acordo com Vacca, ser assim concebido já que "é um pensador com cujo pensamento não pode — ou pelo menos não deve — deixar de debater todo aquele que, depois 
dele, enfrentar os grandes problemas em torno dos quais se atormentou sua reflexão". Para Vacca, poderíamos considerar essa formulação um passo adiante caso se avançasse também no acesso aos "instrumentos que permitam relê-lo em bases filológicas e críticas mais sólidas" e, ao mesmo tempo, garantisse que fosse respeitado o ritmo de desenvolvimento do seu pensamento, imunizando "o intérprete contra a tentação de "forçar os textos"(VACCA, 2010, p. 29).

A ênfase aqui está no fato de que não se deve prescindir do caráter aberto do texto gramsciano, reconhecidamente uma das razões da grandeza do seu pensamento, que guarda em cada argumento uma "inquietação que o sustenta e que o impede de estabelecer posições absolutas e definitivas" (FERRONI, 1999, p. 41). Desta forma, procurar extrair do pensamento de Gramsci, como se fez no passado, orientações imediatas para a ação política ou então concepções de mundo integrais sobre a moral e a cultura, a sociedade e a história, tende a se concretizar como uma operação reducionista e aberta a incoerências. Numa análise criteriosa se poderia advertir que tanto a atenção quanto o reconhecimento da grandeza de seu pensamento "não deveriam colocar-se em um horizonte ideológico predeterminado, em um esquema histórico-político absolutizante, mas sob o signo da abertura, da riqueza de seu próprio caráter fragmentário e inacabado" (FERRONI, 1999, p. 42). Talvez tenha sido essa a razão pela qual, em relação a Gramsci, o neologismo gramscismo tenha se tornado inviável e continue a sê-lo, a despeito de todas as tentações. Gramsci é assim um "clássico" cuja obra bem como o seu tempo - e mais ainda o tempo da sua recepção - não abriram a possibilidade de uma cristalização nos termos do leninismo, do trostskismo, ou mesmo do guevarismo. Sem duvida, um atestado de saúde e vitalidade!

Nessa linha, como estabelecer uma reflexão aberta, critica e questionadora a propósito da temática dos intelectuais vista a partir dos textos de Gramsci? Penso que seria importante examinar a questão dos intelectuais em Gramsci a partir de diversos pontos de vista. Alguns deles já trabalhados e bastante aceitos, outros um pouco menos convencionais, mas que podem jogar uma nova luz nessa relação tão afamada e prestigiada dentro das ciências sociais 
que se dedicou a estudar Gramsci ou o adotou como um autor referente e central para essa problemática.

Seria importante observar, em primeiro lugar, que há uma relação de mão dupla entre Gramsci e o tema dos intelectuais. Gramsci não somente os pensou de maneira diversificada e complexa, com o intuito de redesenhar o tipo de lugar que estes ocupavam tanto na transição quanto no interior da sociedade moderna que em seu tempo se estruturava e se transformava - questão percebida mas não integralmente assimilada por muitos de seus comentadores -, como também há que se registrar que acabou sendo construída uma imagem bastante expressiva do próprio Gramsci como um intelectual exemplar, produtor de um pensamento abrangente, instigante e inovador que mereceria diversos qualificativos conforme a orientação de onde partisse a mirada que tivesse a intenção de desvendá-lo. Enfim, embora pouco comum, pode-se dizer que a própria reflexão gramsciana sobre os intelectuais ajudou a que se formasse em torno dele, conscientemente ou não, uma representação determinada.

Assim, antes de desenvolver a primeira dimensão acima apontada, gostaria de demarcar algumas representações que se cristalizaram em torno da imagem de Gramsci como um intelectual diferenciado. Em primeiro lugar, Gramsci é um pensador que ganha sua identificação mais forte pela mediação da política. Gramsci é um intelectual-político, um dirigente político, um político prático vinculado ao movimento socialista e depois comunista na Itália - e isso é absolutamente preciso visto que toda sua vida madura, antes e depois da prisão, esteve dedicada à estruturação e à organização da ação política dos setores subalternos da Itália, especialmente dos operários da emergente indústria de transformação que crescia no seu tempo e que nucleava suas atenções.

Aprisionado pelo fascismo, seus escritos foram produzidos sob condições absolutamente precárias, o que acabou por cristalizar uma imagem que seria utilizada politicamente (talvez de forma problemática naquela conjuntura) como um "herói" e posteriormente um "mártir" da classe operária italiana. Assim, a primeira imagem construída a respeito de Gramsci seria a de um personagem inserido na cultura heróica do movimento comunista. Uma imagem 
comovente e factualmente verdadeira, mas unilateral, já que não faz jus ao pensador sardo, especialmente em razão da sua postura abertamente crítica tanto ao marxismo da sua época quanto às orientações políticas advindas da Internacional Comunista (IC). Talvez o maior exemplo dessa contraposição entre Gramsci e a IC tenha se dado por volta dos primeiros anos da década de 1930 em relação ao tema da Constituinte na luta contra o fascismo. Concebida por Gramsci a partir de uma estratégia de luta democrática para derrotar o fascismo, a questão da Constituinte se contrapunha flagrantemente à linha política da IC que buscava fomentar a revolução proletária na Itália como processo simultâneo e sucessivo à derrubada do fascismo (ROSSI; VACCA, 2007). É relevante esse aspecto uma vez que explica um isolamento de Gramsci não apenas motivado por sua prisão pelo fascismo mas por uma "condenação" da IC em relação à sua proposta de uma Constituinte para a Itália desde 1929. Vele mencionar que depois da sua morte haveria o reconhecimento de que a reflexão de Gramsci em torno da proposta da Constituinte havia sido efetivamente "uma antecipação da política de Frente Popular" (VACCA, 1999, p. 93). De toda forma, quer assumido por algum tempo uma visão mítica da revolução bolchevique ou tornando-se depois um pessimista em relação àquele movimento (PONS, 2010, p. 170-174), hoje é cada vez mais consensual entre os analistas que as idéias de Gramsci devem ser vistas a partir de uma posição de autonomia em relação ao movimento comunista de sua época e especialmente daquele que se seguiu a ela (AGGIO, 2008).

Assimilada a imagem que o canonizava no interior da cultura heróica comunista, ela iria se desdobrar em outra depois de sua morte, do final da guerra e da primeira edição das Cartas e dos Cadernos do Cárcere. Particularmente na Itália, Gramsci passaria gradativamente a ser visto e legitimado como um ícone que sucederia os pais do socialismo mundial, especialmente a linhagem estabelecida pelo marxismo soviético: Gramsci sucederia Marx, Engels, Lenin e Stalin como a referência mais contemporânea que daria suporte à estratégia da revolução proletária e do socialismo. Com essa cristalização, o pensamento de Gramsci seria lido como um pensamento caudatário do desenvolvimento do marxismo revolucionário mundial, reservado a ele um lugar especial frente à reflexão, que se demandava à época, 
a respeito da estratégia revolucionária nos países centrais do desenvolvimento capitalista. Relevado como "teórico da revolução" nos países avançados, Gramsci perderia nessa leitura os elementos de inquietação intelectual que marcavam um texto escrito não somente numa situação-limite como também um texto obcecado em buscar o entendimento de como enfrentar as novíssimas configurações do novo mundo que se descortinava no seu tempo. A sua transformação em ícone acabaria por afetar sua recepção, tornando-a, no mais das vezes, esquemática, mesmo que se garantisse a ele o perfil heróico de um revolucionário exemplar e mesmo que se validasse nele a inovação a respeito de alguns conceitos e dimensões significativas do pensamento marxista, notadamente aqueles que se referem tanto à temática do Estado ampliado quanto à chamada estratégia da revolução processual.

Apesar disso, a leitura de Gramsci continuou a inspirar algumas reflexões inovadoras sobre os vínculos, os valores e as estratégias políticas que deveriam ser estabelecidos entre os atores políticos e sociais da Itália moderna do pós-guerra. Da mesma forma que havia se processado no período da prisão no qual os escritos de Gramsci projetavam iluminações diferenciadas e agudas sobre os problemas políticos do movimento comunista, os porta-vozes da fase heróica não destruíram integralmente o que havia de instigante no seu pensamento nem impediram novas aberturas e interpretações advindas de rigorosos estudos do seu texto. É possível acompanhar, na Itália do pós-guerra toda trajetória de investigação, tensa e contraditória, que envolveu a relação de Gramsci com os intelectuais agregados culturalmente pelos comunistas italianos (VACCA, 2008).

Um momento de inflexão importante nessa trajetória ocorre com os estudos realizados após a edição crítica dos Cadernos do Cárcere, publicados a partir de meados da década de 1970. Esses estudos abriram novas perspectivas de compreensão do seu pensamento e do seu lugar histórico. A partir daí acentuou-se a convicção de que a originalidade de Gramsci estava concentrada ou nucleada nos elementos que ele havia mobilizado para refletir sobre o tema do "americanismo". Ao lado dessa temática, reconhece-se que principalmente a partir do conceito de revolução passiva emergia uma nova construção bem como novos significados a respeito 
da noção de hegemonia, o que jogava novas luzes em relação às temáticas da filosofia da práxis e dos intelectuais (INSTITUTO GRAMSCI, 1978).

$\mathrm{O}$ argumento era sólido e se sustentava numa releitura da história e das mudanças que haviam se processado na virada do século XX. Para diversos estudiosos, o que havia no texto gramsciano era o firme reconhecimento de que o século XX havia presenciado a mais inaudita emergência de massas na vida pública e na sociedade em geral que toda época da história. Os pesquisadores passaram a reconhecer em Gramsci um pensador que havia reconhecido e assimilado produtivamente essa grande mudança, tornando-a presente, de forma permanente, em toda sua reflexão. Nesse quadro, a revolução bolchevique havia sido, antes de tudo, uma revelação da até então desconhecida possibilidade de ação das massas, mas depois desse momento a questão da revolução se havia complicado em termos reais. As ações dos dominantes também sofreriam uma inflexão em relação às massas, revelando que os métodos repressivos não eram mais inteiramente seguros, sendo necessário acolher, responder e controlar suas demandas e reivindicações. É desse reconhecimento que nasce em Gramsci o conceito de "revolução passiva" que, por sua vez, iria estimulá-lo a pensar na necessidade de um novo tipo de direção política e intelectual para o movimento operário e comunista, que assumisse a política como elaboração consensual, positiva e de reconstrução da ação e da estratégia dos setores subalternos (ZANGHERI, 1999).

O conceito de revolução passiva em Gramsci seria a abertura para uma nova concepção de política que se apresentasse de forma produtiva e com capacidade de intervenção nesse novo cenário, em suas contradições e seus extraordinários desafios. A revolução passiva não seria assumida por Gramsci como um programa político, mas se configuraria como a referência analítica e o instrumento de conhecimento mais importante de toda sua obra. Por meio dele se poderia compreender não apenas o movimento da transição para a ordem burguesa, mas também sua universalização, ultrapassando a interpretação de que esses processos teriam apenas o caso clássico da revolução francesa como paradigma. Por outro lado, após o impacto da revolução bolchevique, tudo indicava que o avanço do 
socialismo em perspectiva mundial se apresentaria obedecendo a uma "fortuna assemelhada às revoluções passivas da burguesia no século XIX, no contexto histórico contemporâneo em que a guerra de movimento cedia lugar à de posição" (VIANNA, 1997, p. 49).

Para Gramsci, o americanismo se apresentava como a modalidade de revolução passiva típica do capitalismo maduro, uma expressão de racionalidade integral com enorme capacidade de universalização. $\mathrm{Na}$ Europa, a política realizaria, das mais diversas maneiras, a intermediação entre as classes do mundo produtivo. Nos países retardatários - não apenas europeus -, avançava-se em direção ao moderno por meio de uma super-estrutura que se colocava à frente dos movimentos da infraestrutura, compensando a defasagem que os caracterizava frente aos países de capitalismo maduro. Em ambos cenários, contudo, haveria saltos e processos moleculares. Seriam modalidades especificas de revolução passiva que teriam vigência histórica, condicionariam e determinariam fortemente os processos de generalização do capitalismo e da ordem burguesa.

É nesse último contexto que o papel dos intelectuais torna-se central na análise gramsciana. Por meio dos intelectuais, o capitalismo encontra uma via de passagem nos países de capitalismo retardatário. Neles, como diria Gramsci, "o impulso para o progresso não é estreitamente ligado a um desenvolvimento econômico local, mas é reflexo do desenvolvimento internacional que envia para a periferia as suas correntes ideológicas"; nesse contexto, "a classe portadora das novas idéias é a classe dos intelectuais e a concepção de Estado muda de aspecto. O Estado é concebido como uma coisa em si, como um absoluto racional" (GRAMSCI, 2002, p. 350). Com precisão cirúrgica, Luiz Werneck Vianna desvenda a razão pela qual em Gramsci o tema dos intelectuais ganhou cada vez mais centralidade: no contexto histórico de retraso do capitalismo "é a política que atua como libertadora das forças produtivas, e não o inverso"; "a revolução passiva seria o contexto do protagonismo políticosocial dos intelectuais" (VIANNA, 1997, p. 53). Para os intelectuais do marxismo essa descoberta colocava um desafio extraordinário: a revolução passiva não seria adotada como um "programa" mas como um "critério de interpretação" no sentido de compreender e interferir no transformismo dos atores que, no fundamental, se 
constituía no núcleo operativo histórico das varias modalidades de revolução passiva. Como afirma Luiz Werneck Vianna, Gramsci "não pretende reverter uma revolução passiva em 'ativa". O seu problema poderia ser colocado nos seguintes termos: era preciso "mudar a chave da direção do transformismo". E, "nessa mudança de chave, a possibilidade de uma tradução do marxismo como uma teoria da transformação sem revolução 'explosiva' de tipo francês" (VIANNA, 1999, p. 78-79).

Com esse movimento interpretativo, Gramsci ultrapassava o espaço italiano, os enquadramentos da cultura heróica e os próprios limites do mundo comunista para ganhar uma nova dimensão. Gramsci passava a ser visto como um intelectual e político advindo do mundo comunista que, a partir de sua postura intelectual de "assimilador onívoro" e, por fim, um "grande eclético" (MANCINA, 1992), teria sido capaz de pensar, a partir do marxismo, os nexos e os termos nos quais uma nova época histórica havia sido produzida: mudança epocal da qual o movimento a que ele estava vinculado dava soberbas demonstrações de incompreensão, revelando uma notável incapacidade para dirigir os vetores dessa nova época e se universalizar.

Como dissemos, essas novas leituras alocariam Gramsci definitivamente num terreno de autonomia no interior do mundo comunista, atribuindo-lhe vigorosos qualificativos de um pensamento que também dava todas as indicações de que o seu núcleo central era a inquirição das diversas modalidades de desenvolvimento do capitalismo, entendido como um fenômeno mundial. Aliada a sua ênfase morfológica para tratar os fenômenos sociais, sua reflexão sobre as diversas subjetividades na sociedade moderna bem como no trânsito para ela, acabaria por fecundar e nutrir um pensamento voltado para a reflexão das conexões possíveis entre modernidade e democracia. Em Gramsci, a busca por espaços e estruturas para expressão das subjetividades emergentes com o moderno sugerem também a necessidade do estabelecimento de uma vida política democrática, concebida a partir de uma perspectiva civilizacional de alcance mundial. Esse movimento interpretativo criaria, por assim dizer, um novo e efetivo "momento Gramsci" para se repensar tanto o contexto em que ele viveu quanto a vitalidade de seu pensa- 
mento. Nessa linha, pode-se dizer que Gramsci passaria a ser cada vez mais assimilado como um pensamento anunciador daquilo que, mais à frente, viria a ser concebido como o intelectual democrático, marcado pela capacidade crítica e pela responsabilidade pública (QUIROGA, 2009).

A contrariu sensu, esse Gramsci foi sendo gestado ao mesmo tempo em que uma retomada do Gramsci heróico foi assumindo uma tardia e revigorada configuração. No contexto de crise das esquerdas ocidentais depois do colapso do comunismo histórico e da crise da perspectiva social-democrática, Gramsci seria cada vez mais equiparado por alguns interpretes às figuras de Trotski e Che Guevara que, além dos perfis heróicos e também trágicos que caracterizou a todos, expressariam orientações investigativas e também políticas bastante distintas daquelas que se estabeleciam com o movimento de reinterpretação do seu texto e das suas circunstâncias históricas, conforme alinhavamos acima. Esse era um Gramsci revolucionário e sua expressão intelectual diretamente proporcional a essa imagem. Nessa leitura, Gramsci se fixava como o perfil mais contemporâneo e hodierno do intelectual revolucionário, e, em conseqüência, seu conceito de "intelectual orgânico" acabaria por sofrer o influxo dessa caracterização: o "intelectual orgânico" de Gramsci seria essencialmente um intelectual revolucionário (militante, heróico), contraposto à incontornável diversidade dos intelectuais de profissão.

Surpreendentemente, esse Gramsci devotado à vontade e à ação - mas distante do "pessimismo da razão" por ele assinalado encontrará sua imagem e semelhança em uma representação mais radicalizada ainda que tem aparecido na direita norte-americana, e de forma paralela tem ganhado corpo entre alguns intelectuais brasileiros, sendo talvez o filosofo Olavo de Carvalho a figura mais notável desta corrente interpretativa (CARVALHO, 1994). O que chama a atenção é que essa direita norte-americana, agressiva e rude na crítica à recente inflexão social-democrata da moderna política norteamericana, compartilha com a esquerda do marxismo sistemático uma visão de Gramsci como alguém que finalmente "completa" a estratégia subversiva dos marxistas, sempre iguais a si mesmos no seu eterno intento de derrubar a ordem, seja como for: desta vez, por meio de uma suposta estratégia processual gramsciana, que se infiltra 
e destrói os valores da cultura, tornando mais fácil a tomada do poder. O revolucionarismo toma conta do personagem, e gramscianos muito bem colocados, com alguma autocomplacência, se alegram com a imagem de que Gramsci, hoje, seria o verdadeiro Lenin, o verdadeiro "perigo". A tolice completa sua obra: o revolucionarismo esquerdista de mãos dadas com os próceres da ideologia conservadora do centro do capitalismo, numa visão plana e instrumentalizada deste que é indubitavelmente um dos clássicos da política do século XX.

A despeito de tudo que se disse acima, esse mergulho no interior das representações que se vem construindo sobre a imagem de Gramsci como um intelectual diferenciado sugere a hipótese de que se avança significativamente da simplória noção de engajamento, como absolutamente insuficiente para dar conta da trajetória intelectual e política de Gramsci, para um adensamento mais significativo que demanda uma nova abordagem do seu texto e conseqüentemente novas proposições analíticas.

Nesse ponto seria importante então refazer o caminho e o argumento central de Gramsci em relação aos intelectuais e ver em que termos ele nos parece ainda válido. Como sabemos, para Gramsci, todo homem é um intelectual, mas nem todos exercem uma função intelectual na sociedade. $\mathrm{Na}$ sua primeira parte, esse conhecido aforismo sustenta a idéia de que todos somos intelectuais porque, como todos os homens, pensamos, projetamos e colocamos em prática ações que nos mantêm vivos, individual ou coletivamente. A segunda parte afirma o critério de que existem funções intelectuais na sociedade que são exercidas por determinadas pessoas. Essas funções são fundamentalmente organizativas, como aquelas exercidas por um jornalista, um professor, um escritor, um arquiteto, um sindicalista, um empreendedor, um policial, e especialmente por dirigentes institucionais que têm a precípua função de organizarem a vida social nas suas mais diversas e complexas dimensões, na esfera pública ou na esfera privada, quer sejam elas muito próximas a nós e muito práticas ou muito distantes e até mesmo etéreas. É um alargamento jamais visto da noção de intelectual, tornado possível apenas no interior dos marcos históricos da modernidade.

Essa formulação contesta a idéia muito em voga no senso comum de que os intelectuais são sábios ou homens das artes e das 
letras desvinculados da vida social. Gramsci divisava que a nova sociedade que emergia no seu tempo havia produzido seus intelectuais em conexão com um avanço sem precedentes da industrialização e da urbanização, o que ocasionaria também uma ampliação sem precedentes da vida mercantil e das funções do Estado. Ele os chamou de "intelectuais orgânicos" para indicar que eram pessoas vinculadas organicamente à sociedade moderna, quer fossem elas do mundo do capital ou do mundo do trabalho. Essa camada de intelectuais estaria fadada a um crescimento inaudito, diversificando suas profissões, conforme avançasse o desenvolvimento do capitalismo moderno. Com isso, a tendência seria a formação daquilo que Gramsci chamou de uma "massa" de intelectuais, elemento importantíssimo tanto na sua teoria quanto na sua estratégia política.

Desta forma, produzidos na e para a superestrutura da sociedade moderna, como seus "funcionários', os "intelectuais orgânicos" não são os mesmos das sociedades pré-modernas. Nestas, os intelectuais atuavam para manter a sociedade amarrada às suas tradições, uma vez que estas garantiriam a sua estabilidade e conservariam intacto o status quo. Por isso, Gramsci os chamou de "intelectuais tradicionais". As sociedades modernas ainda guardariam em seu seio muitos intelectuais desse tipo e eles não jogariam um papel desprezível na organização e na definição dos rumos da vida social.

Vinculados às classes sociais produtivas do mundo do capital e do mundo do trabalho, os novos intelectuais da sociedade moderna, quer estivessem ligados diretamente à produção, como os intelectuais mais técnicos e mais vinculados ao mundo da ciência e da tecnologia, quer aqueles mais ligados às atividades mais convencionais ou às funções administrativas do Estado, exerceriam um papel fundamental na dinâmica e na transformação social. Transcendendo o mundo da produção, esse extrato intelectual, indo além das suas especialidades, estimularia a que os homens refletissem sobre o mundo impulsionando-os no sentido de promover a mudança e a consolidação de situações culturais e políticas que fortalecessem o vetor indicado pela modernidade.

O tema dos intelectuais em Gramsci assume essa centralidade e se desdobra nos diversos argumentos que se expressam, de formas diferenciadas mas também conectadas, nos Cadernos do Cárcere 
no sentido de investigar, elaborar e sistematizar estreitamente seus vínculos com as temáticas do consenso e da hegemonia, da guerra de posições e da revolução passiva, reconhecidamente, os eixos fundadores tanto da profundidade de seu pensamento quanto dos elementos inovadores de uma grande política.

Outra vez aqui reaparece a abertura e a impossibilidade de enquadramento do pensamento de Gramsci. Da mesma maneira em que se observa para outras dimensões do seu pensamento, também no que se refere à questão dos intelectuais "não se pode identificar um esquema absoluto, generalizante, uma forma politically correct de reconstrução das funções do trabalho intelectual, uma instância para a construção do famigerado 'intelectual orgânico', mas pode-se encontrar um horizonte problemático, uma interrogação inquieta e rigorosa, uma atenção voltada para a particularidade das situações e relações concretas"(FERRONI, 1999, p. 43).

Talvez uma crítica necessária ao alcance ou à validade das formulações gramscianas sobre os intelectuais deva partir do reconhecimento de que seus conceitos de intelectual tradicional e orgânico evidenciam hoje muito pouca eficiência analítica diante da realidade atual. O "intelectual orgânico" gramsciano e sua noção de hegemonia - ainda que esta mantenha sua força analítica - pressupunham uma organicidade da sociedade baseada numa dialética que atribuía à atividade cultural a tarefa do controle do conjunto social e cultural, mesmo que este fosse obtido pelo consenso. Tal processo se mostra cada vez mais impossível, quando não ineficaz, tanto mais se pensarmos que Gramsci entendia que sua culminação seria a construção do partido como o "moderno Príncipe". Há que se admitir também que a temática dos intelectuais pensada como oposição e, por vezes, como confrontação entre os intelectuais "orgânicos da burguesia" e os intelectuais "orgânicos do proletariado" seja um resquício arqueológico de uma época e tenha perdido a centralidade que teve no século XX. Assim concebida, ela se afasta de nós como um "momento cultural superado", para usarmos aqui mais um argumento de Ferroni. Por fim, é preciso reconhecer que, como todo grande pensador, Gramsci não deixaria de pagar um tributo ao seu tempo, uma vez que hoje "não apenas deixou de existir a instância organicista unificadora (...) como parece que desmoronou toda função mediadora de consciência 
e consenso e, portanto, toda possibilidade de relacionar o equilíbrio social à elaboração cultural" (FERRONI, 1999, p. 48).

Mesmo assim, Gramsci permanece como modelo metodológico e estímulo para a análise ao introduzir uma saudável tensão bem como uma permanente demanda para que sempre se busque sínteses no terreno da reflexão social e política. Nessa linha de argumentação, Gramsci continua nos auxiliando na necessidade e na urgência de pensarmos, de maneira nova e rigorosa, sobre aquilo que os intelectuais são hoje, no que eles se transformaram e especialmente o que ainda se pode esperar deles. É preciso descobrir o que eles ainda podem fazer, conjugando sua situação particular com a noção de universalidade, para que se fortaleça a razão crítica e para que escapemos da avassaladora submissão ao mercado e à sociedade do espetáculo que nos empolga, mas também nos afoga diuturnamente.

Não há a menor dúvida de que o mundo em que vivemos é bastante distinto do que aquele em que Gramsci viveu. É nítida também a percepção de que o universo intelectual dos dias que correm tem outras configurações e suas relações com a política são muito mais difusas. Há tanto um excesso de vida cultural e comunicativa quanto ameaças permanentes e sólidas à racionalidade crítica. A modernidade enquanto horizonte civilizacional permanece fragilíssima. Num contexto como esse, o desprezo aos intelectuais, especialmente à aguda reflexão sobre eles que se encontra no texto gramsciano, é apenas a garantia de uma vida espiritual pobre, desprovida de qualidade, para não dizer brutal.

The "classicness" of Gramsci and the intellectual theme

Abstract. This article discusses the classical condition of the twentieth century politics which has been attributed to Gramsci by many of his interprets. The subject of the intellectual, as it was established by Gramsci in his Prison Notebooks, will be emphasized in order to think about the Gramsci's own trajectory. Therefore, it will be suggested some new elements for a discussion about his political thought and also about his role in the critical reflection on the relation between the intellectuals and the politics nowadays. For this purpose, the key concepts of what Gramsci called passive revolution will be put in evidence.

Keywords: Antonio Gramsci. Classicness. Intellectual. Passive revolution.

Anos 90, Porto Alegre, v. 17, n. 32, p. 75-91, dez. 2010 


\section{Notas}

${ }^{1}$ Esse artigo foi escrito a partir da intervenção realizada na mesa redonda "A temática dos intelectuais em Gramsci” que integrou o Seminário de Estudos intitulado "Os intelectuais e a Educação - Gramsci e a educação", promovido pelo Grupo de Estudos e Pesquisas em Filosofia da Educação (PAIDÉIA), Grupo de Estudos e Pesquisas História, Sociedade e Educação (HISTDBR) e pelo Departamento de Filosofia e História da Educação (DEFHE) da Faculdade de Educação/UNICAMP, realizado entre 19 e 23 de outubro de 2009. Essa versão foi atualizada tanto em alguns aspectos da sua exposição, visando dar clareza e ênfase aos seus argumentos principais, quanto em relação à bibliografia, agora atualizada com algumas publicações editadas em português. Por fim, agradeço a Luiz Sérgio Henriques, editor do sitio Gramsci e o Brasil, a leitura e comentários a essa versão, eximindo-o de qualquer responsabilidade pelo resultado final.

\section{Referências}

AGGIO, A. O lugar de Gramsci. In: AGGIO, A. Uma nova cultura política. Brasília: Fundação Astrojildo Pereira, 2008.

CARVALHO, O. A nova era e a revolução cultural: Fritjof Capra \& Antonio Gramsci. Rio de Janeiro: Instituto de Artes Liberais \& Stella Caymmi. 1994.

COUTINHO, C. N. Gramsci, um estudo sobre seu pensamento político. Rio de Janeiro: Civilização Brasileira, 1999.

FERRONI, Giulio. Il piensero di Gramsci e Le modificazioni del modelli intelectuali nel Novecento. In: VACCA, Giuseppe (Org.). Gramsci e il Novecento. Roma: Carocci, v. 1, p. 39-50, 1999.

GRAMSCI, A. Cadernos do Cárcere. Rio de Janeiro: Civilização Brasileira, v. 6, 2002.

INSTITUTO GRAMSCI. Politica e história em Gramsci. Rio de Janeiro: Civilização Brasileira, 1978.

LIGUORI, Guido. Roteiros para Gramsci. Rio de Janeiro: Editora UFRJ, 2007.

MANCINA, Claudia. Um grande revisionista. Presença, n. 17, p. 64-69, 1992.

MArramaO, G. O demônio anti-sistemático. Presença, n. 11, p. 150-157, 1988.

PONS, Silvio. O grupo dirigente do PCI e a 'questão russa' (1924-1926). In: AGGIO, A., HENRIQUES, L. S.; VACCA, G. (Orgs.). Gramsci no seu tempo.

Anos 90, Porto Alegre, v. 17, n. 32, p. 75-91, dez. 2010 


\section{Alberto Aggio}

Brasília/Rio de Janeiro: Fundação Astrojildo Pereira/Contraponto, p. 143-174, 2010.

QUIROGA, Hugo. Crítica y responsabilidad pública - a propósito de los intelectuales. In: HIB, Claudia (Comp.). Elpolítico y el cientifico- ensayos en homenaje a Juan Carlos Portantiero. Buenos Aires: Siglo XXI, p. 107-122, 2009.

ROSSI, A.; VACCA, G. Gramsci tra Mussolini e Stalin. Roma: Fazi, 2007.

VACCA, G. Prefácio à edição italiana. In: AGGIO, A.; HENRIQUES, L. S.; VACCA, G. (Orgs.). Gramsci no seu tempo. Brasília/Rio de Janeiro: Fundação Astrojildo Pereira/Contraponto, p. 25-32, 2010.

VACCA, G. Appuntamenti con Gramsci. Roma: Carocci, 1999.

VACCA, G. Gramsci e Togliatti. Roma: Riuniti, 1991.

VACCA, G. Os estudos gramscianos depois de 1989. Site Gramsci e o Brasil. Disponível em: http:/ / www.acessa.com/gramsci/?page=visualizar\&id=886, 2008.

VACCA, G. Por um novo reformismo. Rio de Janeiro/Brasilia: Contraponto/Fundação Astrojildo Pereira, 2009.

VIANNA, L.W. O ator e os fatos: a revolução passiva e o americanismo em Gramsci. In: A Revolução Passiva - Iberismo e americanismo no Brasil. Rio de Janeiro: Revan, p. 28-88, 1997.

ZANGHERI, R. Gramsci e Il Novecento. Considerazioni introduttive. In: VACCA, G. (Org.). Gramsci e il Novecento. Roma: Carocci, v. 1, p. 09-20, 1999.

Recebido em 20/05/2011

Aprovado em 07/06/2011 